\title{
Institutional Texts and the Processes of Meaning Making
}

\author{
Victor Lord Owusu ${ }^{1}$ \\ ${ }^{1}$ Department of Political Science, Carleton University, Ottawa, Canada \\ Correspondence: Victor Lord Owusu, Department of Political Science, Carleton University, 1125 Colonel By Dr, \\ Ottawa, ON K1S 5B6, Canada. Tel: 1-613-619-6233. E-mail: owusulord@ymail.com; victor.owusu@carleton.ca
}

Received: April 13, 2014 Accepted: May 14, 2014 Online Published: July 29, 2014

doi: 10.5539/ijel.v4n4p1

URL: http://dx.doi.org/10.5539/ijel.v4n4p1

\begin{abstract}
Much research has been devoted to the development of analytical systems for linking different parts of texts for the purpose of determining meaning. This article introduces a referencing system meant for analysing institutional policy texts. The referencing system makes it practical to link clauses and sentences with paragraphs and policy objectives with multiple activities of institutional documents under analysis. Based on a hierarchical numbering order, the referencing system revolves around the analytical principles of Halliday's Functional Grammar. Using policy sentences of the International Monetary Fund and Ghana in their relationship, the paper demonstrates how meanings can be determined from institutional policy texts without a reference to institutional authors. Without undermining the contributions of institutional authors to the formulation of institutional policy texts, the paper questions their role in meaning making and refers to institutional authors as "scriptors" of institutional texts.
\end{abstract}

Keywords: functional meaning, hierarchical numbering order, institutional authors, institutional text, linking text, scriptors, text

\section{Introduction}

This paper is rooted in aspects of my doctoral research. Faced with the task of the determination of meanings from policy texts with institutional authors, I turned to functional grammar. Functional grammar provided an excellent methodological base. Functional grammar makes it possible to determine the functions of words, phrases and clauses as they appear in policy documents. However, when it became necessary to analytically link clauses and sentences with paragraphs and policy objectives with multiple activities from institutional authors like the International Monetary Fund and the World Bank, the notion of reference in functional grammar and the concept of intertextuality provided little assistance. Hence, this developed referencing system based on a hierarchical numbering order.

The debate as to where and how meanings from an institutional text should be determined is an old and ongoing one, with the formal or functional processes assuming prominence depending on the analysts. The use of both the formal and functional methods is sometimes encouraged. Interpretive methods and procedures have developed around Speech Act Theory (Austin, 1962; Searle, 1969, 1979), Deconstruction (Derrida, 1974), Content Analysis (Weber, 1990; Krippendorff, 1980) and Chomsky's Transformational-Generative (Thompson, 2004). Regardless of the adopted method, the role of authors in the meaning making process remains contested.

Even more controversial is the contributions of institutional authors in providing interpretation to their authored texts. As institutions, the World Bank, local planning authorities and sovereign states have authored and continue to author policy texts. Institutions are authors. Several issues arise when attempting to find meaning from institutionally authored documents, particularly when trying to establish where questions of interpretation should be directed. Although institutions are like humans in that they can claim existence, they can be addressed and spoken of, it is argued that institutional authors do not exist as human authors. When faced with the task of the determination of meaning from institutionally authored texts, policy analysts find themselves dealing directly with the objectives, activities, clauses and sentences of policy texts and documents. The process of determining meaning from institutionally authored texts is a complex one, not least when trying to analytically link objectives with multiple activities and phrases, clauses and sentences of policy documents.

This article introduces a referencing system that makes the linkages of phrases, clauses, sentences, objectives and activities practical when analysing policy texts. The referencing system is introduced in section four. The 
article begins with a detailed analysis of text and institutionally authored documents. The theoretical position that texts are objects, objects that can be analysed independently with no reference to their authors is presented in the second part of this paper. Part three touches on some analytical principles of functional grammar with several specific examples and illustrations. Using policy sentences, the third section also outlines several procedures for analysing policy texts.

\section{Theoretical Consideration}

A text is a functional language-it performs a function within a particular context. A text is also an object, an object in its own right. This property of texts being objects makes it possible to talk about the meaning(s) from texts (Halliday \& Hasan, 1989, pp. 10-12; Halliday \& Matthiessen, 2004, p. 3). Fairclough (1989) emphasizes this object property of a text. Viewed as objects, Chandler states that texts and "language does have some sort of 'materiality"' (1995, p. 175). Written documents are also texts. Whilst sentences within a document are texts, a document in its entirety is also a text. Documents of institutions, local authorities and sovereign states are also texts. Institutional policy documents have the potential for expressing meaning. Being texts, policy documents of institutions or political entities are objects — objects that can be analyzed in their own right.

When faced with the task of exploring for meanings from a text, an analyst first line of approach will probably be to contact the author. The author should be in the right position to explain her text. The author being referred to in this instance is an individual. The individual who authored the text. The contributions of authors to providing meanings from their texts become complicated when the identified author is institutional, a body or several authors to a text.

Take the case of Ghana and the country's national development plans. No single individual, local authority or government department can claim authorship of the country's development plans and policies. Based on Ghana's constitutional planning arrangements, it is concluded that policy and planning documents are authored by all District Assemblies, Regional Co-ordinating Councils, Ministries, Departments and Agencies and finally compiled into a National Policy Text by the National Development Planning Commission (1992, Ghanaian Constitution).

Within this broad and diverse planning arrangement of institutional authors in Ghana, it is unlikely for any single department, government agency and/or individuals within the national planning hierarchy to claim authorship of policy documents. With no individual, department or agency capable of claiming authorship, surely none of the individuals or bodies involved in compiling these documents would be able to provide interpretation or meaning to these documents as authors. Institutional authors within a national planning arrangement become more difficult to deal with because of the diverse nature of individuals represented in the various planning bodies. The planning bodies are made of civil servants, academics and political appointees who are sometimes even moved between government departments during the period of authoring a document. By specifying the roles of individual planners and policy formulators within an institutional setup like Ghana, this paper is by no means attempting to disregard the very important contributions of such individuals to the formulation of institutional policy documents. These individual can be appropriately referred to as "scriptors", as opposed to "authors" of institutional policy documents.

The preceding analysis establishes the following positions - that institutional policy documents have institutional authors and that the author of a national policy document is the state, the national government. The government in this instance operates within the legal national planning and policy structure. This now again leads to another question. Who is the government that questions of authorship, interpretation and meaning can be directed to? Who can be interviewed as the government when attempting to explore for meanings from national policy and planning texts? The state or corporate authors cannot be isolated and singled out for an interview like an individual author. In an instance like the one just described, the process of exploring for meanings from institutional texts can proceed without a reference to the "scriptors".

Derrida argues along similar lines. He argues for the independent position of written texts. He famously states: "there is nothing outside of the text" (1974, p. 158). Derrida was not in essence denying the existence of a human "scriptor"; he was rather moving the center of meaning making from individuals towards the text. Displacing the centre of meaning making away from "scriptors" and towards the text allows written texts to be viewed as objects; objects that can express meaning. Petrey posits that "performative language not only derives from but also establishes communal reality and institutional solidity" (1990, p. 21). Beardsworth supports this position by stating that "there is no relation to others, and, consequently, no community possible without a practice of writing" (1996, p. 22). Although not being physical entities, organizations and institutions exist and author various documents. Documents authored by institutions confirm their existence. In practice, to introduce 
institutional authors is to introduce written texts. Institutional authors are political or social constructs underwritten by texts.

Possibly faced with the issue of institutional authorship, Chandler was moved to provide a summary of the many theories of where meanings of a text should potentially come from. He arrives at the subjectivist, constructivist and objectivist positions (1995, p. 4). Debating like a subjectivists, Fish (1980) maintained that meaning making rests entirely on the reader of the text; a text is not a text without a reader and a context (Chandler, 1995, p. 5). This work accommodates the objectivist position. The objectivist position is not implying that documents are by themselves going to provide meanings without the contributions of an individual. The argument here is that policy documents of states and institutions are considered as standard texts with no specific individual author where questions of interpretation and meaning can be directed. Being standard policy texts with institutional authors, exploring for meanings from policy documents is to be carried out by an analysis of the texts themselves. No second or third party can occupy the position of an author capable of providing interpretation.

Although scripted by individuals, the meaning and interpretation of institutional documents should come from the documents themselves. It is being argued that standard institutional policy documents do supply sufficient information internally to determine their meaning - that is, the meaning of a document is in the sentences and clauses of its texts. By isolating and examining the various clauses and phrases of a policy text, meaning making can be achieved without recourse to the "scriptors". Any such meaning determined without a reference to the "scriptors" will in this paper come from an analysis of the functions of phrases, clauses and sentences within the policy texts. Functional grammar provides the analytical tools needed to determine meaning without a reference to "scriptors".

\section{Data and Method}

Key principles of Halliday's Functional Grammar are used to demonstrate the working of this referencing system (Halliday, 1985, 1995; T. Bloor \& M. Bloor, 1995; Thompson, 1996, 2004; Halliday \& Matthiessen, 2004). Functional grammar is used to determine institutional intentions or objectives and actions or activities from written documents. The working assumption here is that the policy objectives and activities of institutions are expressed and documented in written texts. A policy objective is any specific policy outcome to which an activity or several activities are aimed at achieving. A policy activity is the policy measure or measures specifically directed at achieving the objective/s. A wide range of data was used to position the study within the framework of Halliday's Functional Grammar and demonstrate the working of the referencing system. Selected policy sentences from documents of the International Monetary Fund and Ghana during their long relationship under the Structural Adjustment Programme and, Ghana's First Medium Term Development Framework (1997-2000) were useful sources of data. My long professional and working relationship with policy documents from a variety of sources informed other constructed examples. The grammar of any written policy text plays an essential role in determining the meaning and functional roles of objectives and activities.

Like human experiences, institutional activities are expressed through the grammar of written text. To adequately describe intentions and actions of institutions, policy documents function as a mode of knowing and a mode of doing (Hasan, Cloran, \& Butt, 1996, p. 8). The modes of knowing and doing are represented in policy texts by the identified nouns (subjects and objects), verbs, adjectives and the rest of what is known generally as the parts of speech. These modes can also be represented by phrases, i.e., noun and verb phrases. The concept of "processes, participants and circumstantial elements" are used in functional grammar to represent the modes of knowing and doing. Further representations (objectives and activities) can also be made through nominal and verbal phrases and groups (Halliday, 1985, 1995; Halliday \& Matthiessen, 2004).

Grammar is crucial to determining functional meaning from policy texts. On grammar, Halliday states: "whatever the final purpose or direction of the analysis, there has to be a grammar at the base" (1985, p. xvi). He further noted that a text analysis "that is not based on grammar is not an analysis at all, but simply a running commentary on a text" (1985, p. xvii). This article is not an analysis of the structures of sentences. However, grammar contributes to policy sentences being standard in form in order for a functional analysis to proceed and crucially, for the referencing system to be applied. Example 1 demonstrates the importance of grammar in making sentences standard for the application of the referencing system.

Example 1: The government development objectives are:

- reducing the rate of inflation from double to single digit

- eliminating polio and child labour

Because of already established rules in English Grammar of which this paper is not investigating, I will normally 
expect to find in some form what the government development objectives will be after the verb "are" and the colon (:) in example 1. As anticipated, two development objectives are duly provided in example 1. Because of the conjunction "and" in the second objective in example 1, I also expected to find a second object directly associated with the verb "eliminating" or a second verb and its subject and object - that is a second clause. A second object is provided. The rules of grammar make sentences standard and thus contribute to their meanings.

Written texts from institutions are not treated as passive or dormant documents by interested parties. Written texts are rather the active means through which formal communication and policy interactions are expressed. Written texts are meant to achieve what is referred to as a "function". As functional grammar emphasizes, meaning is achieved by determining the functions and functional roles of the various parts of speech (processes, participants and circumstantial elements) and relating them to one another within the text. On this mode of meaning making, Hasan, Cloran and Butt conclude: "meanings are brought into being in contexts of functions" (1996, p. 7). The below policy statement illustrates the process of meaning making by using the functional roles of words and phrases.

\section{Example 2: The government divested 50\% of state enterprises because of IMF's concessional loan conditions.}

The grammar of this policy text contain a process (divested), the participants (the government and $50 \%$ of state enterprises), and the circumstantial element that follows "because of" (IMF's concessional loan conditions). Understanding this policy statement entails determining the functional roles of the identified parts of speech and associated phrases. Put in functional grammar terms, understanding this policy statement entails determining the functional roles of the identified processes, participants and circumstantial elements. The derived meaning of this policy statement is only achieved when the functions of the process is directly linked to the functional roles of the participants and circumstantial elements.

A description of the functional roles being performed by the process, participants and circumstantial elements in example 2 is another way to demonstrate how meaning is derived. The functional role of the process (divested) is to provide a description of the "actions" performed by the first "participant" (the government). The functional role of the circumstantial element (IMF's concessional loan conditions) is to provide a reason for the government's "action" on the second "participant" (50\% of state enterprises). The function of the process (divested) is being understood within a specific context - the context in this instance being the liberal economic discourse of the IMF and the World Bank. Outside the context of this liberal economic discourse, the functional role of the second participant (50\% of state enterprises) could mean something entirely different depending on the process or perhaps the circumstantial element.

The referencing system acknowledges that functional grammar employs an analytical system based on the notion of ranks. The notion of ranks states that a sentence is made of one or more clauses, a clause consists of one or more groups, a group consists of one or more words, and a word consists of one or more morphemes (Halliday \& Matthiessen, 2004, pp. 6-11, 21-23, 588). Like the referencing system, analysis in functional grammar is done at the rank of the clause. What this means is that paragraphs have to be broken down to sentences and sentences have to be broken down to clauses for any analysis to proceed.

It is at the rank of the clause that we can talk about human experience and institutional actions. When used in a clause, we understand that boys, girls, women and men all refer to humans. When also used in a clause, we understand that words like under, on, and around refer to relative locations. It is also at the rank of the clause that analysis of our existence and how we feel in our environment can be done (Halliday \& Matthiessen, 2004, p. 29). The rank of the clause allows us to express institutional actions like develop, remove, construct and non-physical actions like dependence and reliance. These physical and non-physical actions and intentions dominate institutional policy and planning objectives and activities.

The clause is "not only a figure, representing some process - some doing or happening, saying or sensing, being or having - with its various participants and circumstances; it is also a proposition, or a proposal, whereby we inform or question, give an order or make an offer, and express our appraisal of and attitude towards whoever we are addressing and what we are talking about" (Halliday \& Matthiessen, 2004, p. 29). When policy clauses are analyzed, we are able to determine institutional or state intentions, promises and objectives, what the institution current and future actions and activities are going to be and why the institution is acting in a particular way. We are also able to determine who the various participants and beneficiaries of the government's activities are to be. We will also be able to determine the specific location of activities of the government.

Written policy clauses could be independent- that is they make it possible for the built in clause to potentially express a complete meaning or they could be dependent - that is expressing part of the meaning whilst the rest is deduced from related words and phrases within the policy sentence. Example 3 below illustrates this 
dependent—independent relationship within a written policy clause.

Example 3: The Regional Authority will construct a school at Adum in March 2015 because of the area's rising population.

The clause "the regional authority will construct a school" when analyzed separately provides useful information regarding the potential meaning inherent in the sentence. Without the phrases that follow the preposition "at", the sentence would have been one independent clause. The phrases "at Adum, in March 2007 and because of the area's rising population" when analyzed individually will not potentially yield any meaning. These three phrases however contain very useful information essential to obtaining the full meaning potential inherent in the sentence. The clause "the regional authority will construct a school" is therefore dependent on the three phrases that follow the preposition "at" for its complete meaning. The phrases:

a. at Adum - provides information on the specific location of the school.

b. in March 2015-provides information on the month and year the school will be built.

c. because of the area's rising population - provides information on why the school is being constructed.

Apart from the fact that a written clause can specifically be used to express doings and happenings, clauses also generally contain three other important roles - theme, rheme and subject. The theme is what the message is concerned with. The theme appears as a nominal group, an adverbial group or a prepositional phrase (Halliday 1985, pp. 36-39; Halliday \& Matthiessen, 2004, p. 58). Next is the rheme, the constituent of the text that contains the rest of the policy information (Halliday \& Matthiessen, 2004, p. 64). In example 4 below, the theme is the nominal group "the current consultations between the Government and the World Bank". The rheme follows the theme in example 4.

Example 4: The current consultations between the Government and the World Bank will lead to more concessional loans.

The subject is the entity (the who or the what) that performs the action in a policy text. The subject is the element within the policy text that is responsible for the measures to be implemented (Halliday \& Matthiessen, 2004, p. 59). Additionally, the subject when identified tells us the person, the place, the thing or the idea under consideration. Subjects can appear in different forms as demonstrated in the table below.

Table 1. Types of subject

\begin{tabular}{ll}
\hline Subject as & Subject in Italics \\
\hline Noun & Students will construct the path \\
Phrase & The Local Council will develop the site \\
Gerund & Building is very difficult \\
Infinitive & To demolish is easier than to build \\
Clause & Playing football is prohibited is known by all \\
Citation & Not fit for purpose is often heard these days from politicians \\
\hline
\end{tabular}

All arguments, complaints, regrets or otherwise about the acceptance of a loan condition between a state, the IMF and the World Bank occur through the policy clauses of written texts. Halliday appropriately concludes that when written texts are used to exchange information, "the clause takes the form of a proposition. It becomes something that can be argued about — something that can be affirmed or denied, and also doubted, contradicted, insisted on, accepted with reservation, qualified, tempered, regretted and so on" (1985, p. 70).

In the process of determining meaning, the clause is central. Being able to isolate a clause from an institutional text is key to the process of determining meaning using the referencing system. The clause enables policy analysts to build up a mental picture of reality. It is this building up of a mental picture of reality that makes the clause functions as the representation of processes. In functional grammar, a clause can be represented as a process. For analytical purposes in this article, the terms clause and process will not be used interchangeably. A clause will always be referred to as a clause. A clause may consist of the process itself, participants in the process and circumstantial elements associated with the process (Halliday, 1985, p. 101; Halliday \& Matthiessen, 2004, pp. 169,170$)$. It is the working together of processes, participants and circumstantial elements that bring to 
reality human experience from a written institutional text.

Although it is to be realized that processes are represented by verbs or a verbal group and that participants are represented by nouns when determining the functional roles from a policy text, it is also essential to recognize that in the act of meaning making, policy analysts do not stick to categories like verbs or nouns for the determination of functions or functional roles. The functional roles are what determine the functions and not always the representation of an activity by a process. On this position, Hasan, Cloran and Butt conclude: "there is no fixed notion of subject or nominative or finite or whatever" (1996, p. xix); and "it is an unreasonable imposition on theory to assume that in each sentence or clause of any natural language there is an underlying subject" (1996, p. xx). Hasan, Cloran and Butt were reiterating Firth's position on the determination of functional categories. They said with reference to Firth's position: "every analysis of a particular 'language' must of necessity determine the values of ad hoc categories to which traditional names are given" (1996, p. xx).

In example 3 for instance, the activity of the government is represented by a verb. In the policy statement in example 5 below, the activity is represented by a noun and there is no apparent mention of a subject. As indicated, the determinations of roles are based on the functions being performed by the individual words or phrases in the policy statement.

\section{Example 5: The divestiture of state enterprises is fully operational.}

Undeniably, the activity in example 5 is represented by a noun (divestiture), and not a verb. Within the context of a national planning text, it is only the government that can carry out the divestiture of state enterprises. What this means is that even though the subject is not explicitly mentioned, it is definitely implied that the unmentioned subject is the government. Following from the above, it is possible to encounter a situation where the processes divest or invest in a state policy text is represented by the nouns investment or divestiture in a local planning document. Apart from appearing as verbs, processes can also appear as verbal groups (Halliday and Matthiessen 2004, 335). In example 6 below, the finite and predicator are in italics. The finite verbs "has been" are appearing first, followed by the predicator "negotiating".

Example 6: The Government has been negotiating with the World Bank since July 2005.

When attempting to determine the meaning from an institutional text, it is important to recall that participants are realized by a noun or a nominal group. A nominal group like a noun specifies a thing (Halliday 1985, 159 and 175). In example 7, the nominal group is in italics.

Example 7: All remaining unpaved rural roads will be renovated next year by the Regional Authority.

The nominal group in example 7 contains the main noun "roads" preceded by various items all characterizing the roads in question. The other items characterizing the roads all form part of a detailed set of categories (Halliday, 1985, pp. 162-167; Halliday \& Matthiessen, 2004, pp. 312-327). The categories are meant to isolate the functional role of the individual words in the nominal group. They can be referred to as pre-modifiers. In example 7, the "things" being referred to are "roads". "Things" could appear as count or mass nouns, conscious or unconscious beings, or sometimes in the form of an organized category like a single-carriage highway. Example 7 contains only pre-modifiers. However, there are instances where policy analysts will have to deal with post-modifiers from institutional texts. Example 7 also contains the verbal group (will be renovated) and circumstantial elements (next year by the Regional Authority).

In an institutional text, circumstantial elements appear either as prepositional phrases or adverbial groups. Circumstantial elements are associated with or attendant on the sentence or the clause. They appear mainly as phrases attached to a complete policy sentence. Not only do they provide a framework for identifying the subjects and objects of a written policy text, circumstantial elements also provide a framework for locating and isolating the processes in clauses. To enhance the meaning of a sentence, circumstantial elements serve as an expansion of what is being written about (Halliday, 1985, p. 189). There are several circumstantial elements in functional grammar. Whilst the circumstantial element of "cause" deals with the reason and intended condition why a policy is being actualized, that of "extent" focuses on the unfolding of the policy in space and time. The circumstantial element of "manner" deals with the means of carrying out the policy and that of "matter" focuses on that which is described, referred to or narrated about in the policy sentence (Halliday \& Matthiessen, 2004, pp. 261-262, 355)

An illustration of the use of the various circumstantial elements using three quotations is provided in table 2 below. The first quotation is from an IMF document of the SAP programme and the others are from a Ghanaian national planning document called the First Medium Term Development Framework (FMTDF) 1997-2000. The second quotation is a macro-economic stability objective and the third is an activity from the same plan. 
Quotation 1. Fiscal policy has been directed at raising government savings and lowering the overall budget deficits (Kapur et al., 1991, p. 3)

Quotation 2. Mobilising sufficient revenue for development (FMTDF, 1997, p. 105).

Quotation 3. Reduce budget deficits (FMTDF, 1997, p. 105).

The quotations are first analysed using the principles and categories of functional grammar in Table 2 to establish the relevant categories.

Table 2. Circumstantial elements illustrated

\begin{tabular}{llll}
\hline $\begin{array}{l}\text { Circumstantial } \\
\text { Elements }\end{array}$ & Quotation 1 & Quotation 2 & Quotation 3 \\
\hline Matter & Fiscal Policy & $\begin{array}{l}\text { Macro-economic Stability } \\
\text { Objective }\end{array}$ & $\begin{array}{l}\text { Macro-economic Stability } \\
\text { Activity }\end{array}$ \\
Processes & Raising and Lowering & Mobilising & Reduce \\
Goals & Government Savings and & Sufficient Revenue & Budget Deficits \\
& Budget Deficits & & \\
Means & Unspecified & Unspecified & Unspecified \\
Beneficiary & Unspecified & Unspecified & Unspecified \\
\hline
\end{tabular}

Embedded in a policy clause are the various activities under analysis. Be it physical or non-physical, these activities can be expressed by a process. Functional grammar makes use of six process types-material, mental, relational, verbal, existential and behavioural (Halliday \& Matthiessen, 2004, p. 171). Examples mainly from the first three are used in this article. The process type identified in the policy text can appropriately describe the text in question. For instance if the process identified is mental, it will not be wrong to call the clause a mental text.

Material processes are processes of doing and happening. Material processes express the notion that some entity does something - which may be done to some other entity. In the case of one entity doing something to another entity, the other entity may be the one that is brought into being by the process; not pre-existing. For instance, the government announces that it is going to build a university in the north. The process "build" is going to eventually lead to a university that never existed. There are "'doing to' or dispositive type and a 'bringing about' or creative type of material process" (Halliday, 1985, pp. 103-104; Halliday \& Matthiessen, 2004, p. 179).

In a clause with a material process, there is always one participant- the actor. This participant brings about the unfolding of the process through time, leading to an outcome that is different from the initial phase. As in the example of building a university in the north, the outcome that is different from the initial phase of the unfolding is the built university. The actor is typically also the subject. There are situations where in a clause with a material process in a policy text, the resultant outcome may be confined to the actor, in which case there is only one participant in the clause. Such a happening material clause is intransitive (Halliday \& Matthiessen, 2004, pp. $179,180)$. The material clause in table 3 is an intransitive one.

Table 3. Intransitive material clause

\begin{tabular}{ll}
\hline Actor & Process \\
\hline The Economy & Grew \\
\hline
\end{tabular}

There are other situations where in a material process clause, the unfolding of the action may extend to another participant referred to as the goal- "goal" means "directed at" (Halliday \& Matthiessen, 2004, p. 180). Any such doing material clause is transitive. Table 4 demonstrate a transitive material clause. 
Table 4. Transitive material clause

\begin{tabular}{lll}
\hline Actor & Processes & Goal \\
\hline The Government & Will Grow & The Economy \\
\hline
\end{tabular}

Whilst in the intransitive example the doing (growth) is confined to the economy; in the transitive example, the doing (growth) is being extended to the economy by the government. The economy in the transitive example is the "goal". Not all material processes do represent events that can be described as concrete or physical; they may represent events that are abstract doings and happenings. Not all institutional actions and intentions can be described as physical. Example 8 below illustrates this form of abstract doing. Although intangible, inflation is being presented as a physical activity.

\section{Example 8: Inflation has destroyed national savings.}

There are other instances where a clause might not be referring to an abstract or a material action. In some instances, the analysis might be about "what we think and feel". Situations of this nature involve what goes on in our minds, our mental understanding of what is going on around us. A mental process captures this situation. Mental processes are concerned with our experience of the world of our consciousness. In a clause with a mental process, there is mostly one human participant. This is the one that senses-feels, thinks or perceives (Halliday and Matthiessen 2004, 197-201; Halliday 1985, 105-108). In example 9, the National Development Planning Commission is construed as a human with consciousness.

\section{Example 9: The National Development Planning Commission disagrees with the district proposals.}

The third category of processes of particular relevance to this paper is relational. The main property of a relational process is "being". This is not "being" in the sense of existence. It is "being" in the sense of a relationship. A relationship of "being" is thus being established between two entities (what is being written about and how to achieve what is being written about) because of the relational process. A relationship between two entities is being established by the relational process fixing the identity of the target element in one of two ways: either by specifying its form, how it is recognized, or by specifying its function, how it is valued. Relational processes serve to establish an attribute and to identify. In the identifying category of a relational process, one entity is used to identify another. The identifying category is also meant to express a relationship between objects; one entity is being related to another by a feature of time or place or manner (Halliday, 1985, pp. 114-119, 321; Halliday \& Matthiessen, 2004, pp. 210-213). The next section on the referencing system provides more details on relational processes and their application.

There are instances where a written policy sentence may deviate from its assumed standard appearance- - that is when words in a policy clause are used non-literally to denote something. Under such circumstances, the notion of grammatical metaphor is employed to bring out the meaning from the policy text. When words are used non-literally, it is treated as a metaphor. In functional grammar, metaphors have an expanded meaning. The emphasis is on how meanings are expressed and not on how words are used. This broader understanding of metaphors deals with the situations where meanings are realized by a selection of words that are different from the ones originally used. In the process of determining meaning, metaphorical clauses can be treated either as they appear or by changing such clauses to their congruent or literal form (Halliday, 1985, pp. 320-321). For example, the metaphorical clause Twelve noon saw the minister in Kumasi can remain in its original form as in Table 5 or reworded as in Table 6.

Table 5. Metaphorical sentence form

\begin{tabular}{llll}
\hline Senser & Mental Process & Phenomenon & Place \\
\hline Twelve Noon & Saw & The Minister & In Kumasi \\
\hline
\end{tabular}

Table 6. Congruent sentence form

\begin{tabular}{llll}
\hline Actor & Material Process & Place & Time \\
\hline The Minister & Arrived & In Kumasi & At Twelve Noon \\
\hline
\end{tabular}


As with metaphorical policy clauses like the ones in tables 5 and 6 , the metaphorical form ignores the fact that twelve noon is not conscious, and the congruent form ignores the fact that this was not what was written. What is crucial here is that metaphorical clauses can be made congruent where appropriate. Therefore, regardless of the form an institutional policy clause takes, it can still be analysed functionally for the purpose of meaning making and applying the referencing system.

The term metaphor is used to refer to just one of such non-literal uses of words. Metonym - a word that denotes one thing but refers to a related thing is another example, i.e. Ghana believes that the World Bank will act accordingly; and sometimes synecdoche - in which a part is used for the whole, the whole for a part, the specific for the general, the general for the specific, or the material for the thing made from it. Functional grammar accommodates the use of metaphor, metonym and synecdoche. Nominalization is another form of grammatical metaphor. By nominalization, processes (congruently worded as verbs) and properties (congruently worded as adjectives) are reworded metaphorically to bring out their meanings (Halliday and Matthiessien 2004, 658). Having outlined some key working principles of functional grammar relevant to the referencing system, the discussion now moves to the referencing system itself.

\section{Results and Discussion}

Institutional texts are complex policy documents that are meant to bring to the open the intentions and actions of actors - the state or a corporate entity. In the process of meaning making, policy analysts link sentences with phrases as they break down paragraphs into workable form. The referencing system is meant to make this linkage practical. Further, this micro analytics framework is meant to demonstrate how the principles of functional grammar can be applied to an analysis of institutional policy documents. Although the analysis in this article is being done at the rank of the clause as is consistent with the principles of functional grammar, institutional policy texts are not only written as clauses, but as compound and complex sentences and paragraphs. This system accommodates simple and complex clauses, sentences and paragraphs.

A clarification of the notion of first, second and third is here provided. The notion of first, second and in some cases third processes, participants and circumstantial elements is being introduced because of the manner in which most institutional policy documents are written. The notion of first does not mean that any such goal or process labelled as such is the most important. It is rather the sequence of their occurrence in some policy texts that brings about this labelling. Policy texts in most cases are made of one or more identified objectives and activities under each major topic or sub-topic and, they start by stating that the government's objective or activity is $\mathrm{X}, \mathrm{Y}$ or $\mathrm{Z}$. From example 10 below and with reference to functional grammar, the relational process from the stated objective of example 10 is "is". Thus, the first process and by extension the first goal in example 10 immediately follows the relational process "is". Hence, in example 10, the first process is "promote" and the second is "remove". The first and second goals are "private investment" and "legal obstacles" respectively.

\section{Example 10: Economic stability programme aim is:}

i. promote private investment and remove legal obstacles to growth.

As relational processes serve to characterise and identify, in example 10 (and where a relational process appears after the topic), the relational process serves to identify the objectives and activities directed at achieving the goal. In the case of example 10, the goal is "economic stability programme". The use of a relational process as is demonstrated in examples 10 and 11 and as illustrated in figure 1 before specifying the individual objectives and/or activities made it possible to establish a direct linkage and relationship between the topics "economic stability programme" as in example 10 above and "macro-economic stability" as in example 11 below, and the various stated objectives or activities as they appear in the figure below. Figure 1 demonstrates the use of the referencing system. The referencing system allows stated objectives or activities, i.e. macro-economic stability to be directly linked to the topic. For instance, the topic "macro-economic stability" as in example 11 that is being analysed has four individual identified activities specified after the relational process. In this instance, the relational process is "are".

\section{Example 11: The activities for macro-economic stability are:}

i. Reduce the rate of inflation.

ii. Mobilise sufficient revenue for development.

iii. Promote private investment by removing foreign exchange controls and supporting local industrialist.

iv. Encourage domestic savings and minimise government borrowing.

The four separate specified activities (numbered i-iv) are all appearing after the relational process, which is the 
verb "are". The referencing system is based on a hierarchical numbering order. A hierarchical numbering order is being used because of the multiple occurrences of activities and objectives associated with some topics in institutional policy texts. Apart from catering for the multiple occurrences of activities and objectives where applicable, the hierarchical numbering order is used to express the complexity of the syntactic form found in objectives and activities.

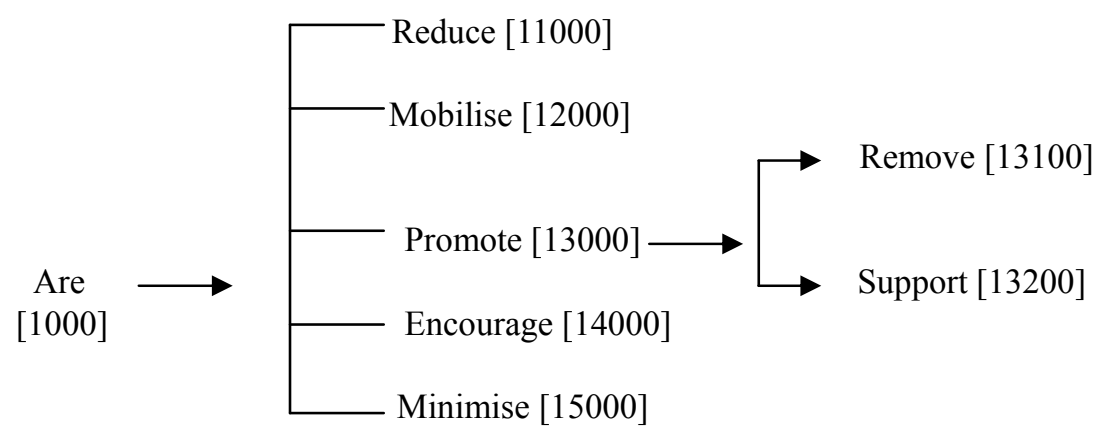

Figure 1. Graphical demonstration of hierarchical numbering order

The referencing system works in this way. The clause containing the topic, "macro-economic stability" as in example 11 and the relational process "are" that comes before the actual specifying of the activities or objectives is numbered [1000]. The individual activities or objectives are numbered from [11000], [12000], [13000] onwards. Apart from representing actual objectives or activities, [11000] or [12000] also represents the first identified process of an objective or activity.

Because the analysis is being done at the rank of the clause, individual clauses within an objective or activity have a number linked to the hierarchical numbering order. For instance, the clauses numbered [13000], [13100] and [13200] are all linked to the activity having the base number of [13000] as in example 12 below. Where appropriate, individual clauses are represented by processes appearing only as verbs; i.e. "promote", as in figure 1 for the entire clause "promote private investment" from example 11. This linkage is illustrated with activity iii from example 11 above and graphically demonstrated in figure 1. The resultant demonstration is example 12 below.

Example 12: Promote private investment by removing foreign exchange controls and supporting local industrialists.

Number $13000=$ Promote private investment

$$
\begin{aligned}
& 13100=\text { Removing }(\text { Remove) foreign exchange controls } \\
& 13200=\text { Supporting (Support) local industrialists }
\end{aligned}
$$

Activity iii from example 11 with the base number [13000] in figure 1 has three identified clauses; [13000], [13100] and [13200]. The three clauses are analysed separately. Clauses [13100] and [13200] are represented by the processes "remove" and "support" respectively and not the gerund "removing" or "supporting". Three separate clauses and therefore, three processes (promote, remove and support) and three goals (private investment, foreign exchange controls and local industrialists) respectively are isolated for activity iii from example 11. They are all linked by the base number [13000]. Further, clauses [13100] and [13200] that are separated by the conjunction "and" are the means for activity [13000].

Because of the conjunction "and" in activity [13000], the two means clauses, [13100] and [13200] are of the same analytical level. Being of the same analytical level, clauses [13100] and [13200] are capable of having separate circumstantial elements in addition to the separate goals already identified. Being circumstantial elements for activity [13000], the two means clauses [13100 and 13200] are represented by the same base number [13000].

The use of the conjunction "and" and the preposition "by" in activity [13000] brings to the fore the interdependency of clauses within an objective or activity of a policy document. When it comes to exploring for functional meanings from a sentence, some clauses are not totally independent. This type of interdependency in functional grammar is referred to as taxis. The two types of interdependency are parataxis (equal status) and 
hypotaxis (unequal status). Hypotaxis deals with the relation between a dependent clause and a dominant one, the element on which it is dependent. Parataxis is the relation between two like clauses, one initiating and the other continuing (Halliday \& Matthiessen, 2004, p. 374).

The choice between parataxis and hypotaxis clauses describes the relation between two clauses within an activity or objective in a clause complex. Clause complexes are often formed out of a mixture of parataxis and hypotaxis clauses. Where appropriate, hypotaxis and parataxis clauses together bring out the meaning in an activity and an objective as is illustrated in activity iii from example 11 above. In example 11 above, clause [13000] is the independent clause whilst clauses [13100] and [13200] are the dependent clauses. Though clauses [13100] and [13200] are independent in relation to one another, both are dependent on clause [13000] for their "full and complete meaning". Because they are independent, hypotaxis clauses conceal lots of information, including all the circumstantial elements. Hypotaxis clauses can easily go by as political statements because they might have no direct policy implications on the actual working of the institutions concern.

Although the conjunction "and" links the two clauses of activity "iv" in example 11 together, the same conjunction "and" could have equally led to a split in the activities. Being parataxis, the two identified clauses of activity "iv" from example 11 are independent, with none dependent on the other. Because of this, they have been separated and given distinct numbers as shown in figure 1. Where appropriate, this separation of independent clauses can occur. With regard to activity "iv" from example 11, the clause "encourage domestic savings" is represented by [14000] in figure 1 whilst the clause "minimise government borrowing" is represented by [15000] in figure 1. Clause [15000] is not considered a circumstantial element of clause [14000]. Technically, clause [14000] alone should have had the number "iv", whilst clause [15000] should have had the next number " $\mathrm{v}$ " in the numbering system in the hierarchy. Though all analyses are done at the rank of the clause as is consistent with functional grammar, it is the totality of the meanings of all clauses analysed within an objective or activity that brings out the functional meaning being sought for from an institutional policy document. Therefore, the functional relation is not only between the topic and the immediate clauses following the relational processes, but all parataxis and hypotaxis clauses within an objective or activity from the isolated institutional text.

\section{Conclusion}

Institutions will continue to author text and policy analysts and researchers will always be confronted with the issue of the determination of meaning from institutional texts. Using the analytical principles of functional grammar as a basis, this paper introduced a developed referencing system based on a hierarchical numbering order for use in the process of determining meaning from texts. As a methodological tool, the referencing system makes it practical to link the clauses, sentences and paragraphs of a text in a holistic form. Although this article centred on institutional texts, its application can be extended to individually authored texts. It is not a method meant entirely for institutional texts.

The method outlined in this paper evolved around one specific form of text analysis-functional grammar. Functional grammar is about deriving functional meanings from texts within a situational context. An essential feature of functional grammar is that it does not come with a set of rules or a formula for analysing texts. Instead, the method is equipped with a set of tools that are used to analyse texts. The emphasis on tools rather than rules makes the method inherently flexible. The developed hierarchical numbering system as presented above emerged as a result of the flexibility of functional grammar. The numbering system fully accommodates the analysis of simple, compound and complex policy sentences. The following three-fold purposes are associated with the numbering system: the unique identification and tracking of analysed clauses and sentences, the establishment of a direct linkage between objectives and activities of texts being analysed in a continuous chain and the provision of a tool for a comparative analysis of two or more documents.

\section{References}

Austin, J. L. (1962). How To Do Things With Words. Oxford: Clarendon Press.

Beardsworth, R. (1996). Derrida and the Political. London: Routledge.

Bloor, T., \& Bloor, M. (1995). The Functional Analysis of English: A Hallidayan Approach. London: Arnold.

Chandler, D. (1995). The Art of Writing. A Media Theory Approach. Aberystwyth: University of Wales.

Derrida, J. (1974). Of Grammatology. Baltimore: John Hopkins University Press.

Fairclough, N. (1989). Language and Power. Harlow: Longman.

Fish, S. (1980). Is There A Text In This Classroom? The Authority of Interpretive Communities. Cambridge: 
Harvard University Press.

Government of Ghana. (1997). First Medium Term Development Framework (1997-2000). Accra. NDPC.

Halliday, M. A. K. (1985). An Introduction to Functional Grammar. London: Edward Arnold.

Halliday, M. A. K. (1995). An Introduction to Functional Grammar. London: Edward Arnold.

Halliday, M. A. K., \& Hasan, R. (1989). Language, Context and Text: Aspects of Language in a Social-Semiotic Perspective. Oxford. Oxford University Press.

Halliday, M. A. K., \& Matthiessen, C. M. I. M. (2004). An Introduction to Functional Grammar. London. Arnold.

Hasan, R., Cloran, C., \& Butt, D. G. (Eds.). (1996). Functional Descriptions. Theory in Practice. Amsterdam: John Benjamin Publishing Company. http://dx.doi.org/10.1075/cilt.121

Kapur, I., Hadjimichael, M. T., Hilbers, P., Schiff, J. \& Szymczak, P. (1991). Ghana: Adjustment and Growth, 1983-1991. Washington: International Monetary Fund.

Krippendorff, K. (1980). Content Analysis. An Introduction to its Methodology. London: SAGE Publication.

Owusu, V. L. (2009). The Making of Development Policies and Plans. The Case of Ghana's Relationship with the International Monetary Fund and the World Bank (Unpublished doctoral dissertation). University of Sheffield, Sheffield.

Petrey, S. (1990). Speech Acts and Literary Theory. London: Routledge.

Searle, J. R. (1969). Speech Acts. An Essay in the Philosophy of Language. Cambridge: Cambridge University Press. http://dx.doi.org/10.1017/CBO9781139173438

Searle, J. R. (1979). Expression and Meaning. Studies in the Theory of Speech Acts. Cambridge: Cambridge University Press. http://dx.doi.org/10.1017/CBO9780511609213

Thompson, G. (1996). Introducing Functional Grammar. London: Arnold.

Thompson, G. (2004). Introducing functional Grammar. London: Arnold.

Weber, R. P. (1990). Basic Content Analysis. London: SAGE Publications.

\section{Copyrights}

Copyright for this article is retained by the author(s), with first publication rights granted to the journal.

This is an open-access article distributed under the terms and conditions of the Creative Commons Attribution license (http://creativecommons.org/licenses/by/3.0/). 